\title{
MOBILIDADE DOS CONSTITUINTES DE ROCHAS BÁSICAS DE SÃO PAULO DURANTE O INTEMPERISMO
}

\author{
A. G. MONIZ*, A. C. NASCIMENTO** e J. E. de PAIVA NETTO***
}

ABSTRACT Weathering of basaltic rocks was studied from both the chemical and the mineralogical points of view. Samples of fresh rock and the two first weathered layers were analysed. Many of the samples of the two weathered layers were in high degree of weathering, with Ki values as low as 0.49 . According to the chemical composition of 48 fresh rocks, the parent basaltic rock was of the tholeiitic type.

Gibbsite and goethite were the only two secondary mineral indentified. Clay minerals of the $7.2,10$ and $14 \AA$ groups were not identified by X-ray diffraction analysis. In the more weathered layer, DTA analysis showed sharp endothermic peaks at $120^{\circ} \mathrm{C}$, which seemed to be due to amorphous gels.

The decrease or increase of the weathered rock constituents was calculated assuming titanium oxide or aluminum oxide be static constituents in both fresh and weathered rocks. The calculations were based on both chemical analysis of the fresh and on the average of 48 chemical analysis of basaltic rocks from the State of São Paulo. Correlations between the four different ways of calculation were established.

The best results, according to correlation values, were obtained assuming that the titanium oxide content did not change appreciably and taking as reference chemical analysis of the corresponding rock. The following constituents presented significant correlations: $\mathrm{SiO}_{2}, \mathrm{Al}_{2} \mathrm{O}_{3}, \mathrm{MgO}$, $\mathrm{Na}_{2} \mathrm{O}, \mathrm{MnO}, \mathrm{K}_{2} \mathrm{O}, \mathrm{CaO}$ and $\mathrm{Fe}_{2} \mathrm{O}_{3}$.

The losses of elements, in decreasing order, were of $\mathrm{CaO}, \mathrm{Na}_{2} \mathrm{O}, \mathrm{MgO}, \mathrm{K}_{2} \mathrm{O}, \mathrm{SiO}_{2}, \mathrm{MnO}$, $\mathrm{P}_{2} \mathrm{O}_{5}, \mathrm{Al}_{2} \mathrm{O}_{3}$ in the more weathered layer and of $\mathrm{Na}_{2} \mathrm{O}, \mathrm{K}_{2} \mathrm{O}, \mathrm{CaO}, \mathrm{SiO}_{2}, \mathrm{MnO}, \mathrm{MgO}, \mathrm{P}_{2} \mathrm{O}_{5}$, $\mathrm{Al}_{2} \mathrm{O}_{3}$ in the less weathered layer. Some calcium and magnesium were retained in the less weathered layer.

Considering the decrease or increase of alkaline and alkaline-earth elements on a cationic basis, it was found that the $\mathrm{Na}^{+}$ion was the most easily lost and the $\mathrm{Mg}^{2+}$ ion the least from both layers and that there was a tendency for the $\mathrm{Ca}^{2+}$ ion to be more retained than the $\mathrm{K}^{+}$ion in the less weathered layer.

INTRODUÇÃO Extensos derrames e intrusões de rochas de natureza basáltica ocorrem na bacia do Paraná, podendo-se destacar os estudos efetuados nessas rochas por Almeida (1946), Leinz (1966) e Rüegg (1969). Essas rochas, ao se decomporem, propiciam a formação de solos de grande importância agrícola, quer pela sua alta fertilidade natural, quer pela grande extensão que ocupam.

No Estado de São Paulo, Paiva Netto e Nascimento (1957) realizaram os primeiros estudos de alteração de rochas basálticas, os quais foram prosseguidos por Melfi (1967). Recentemente, iniciaram-se estudos mineralógicos quantitativos, com ênfase no estudo da fração argila, de solos derivados dessas rochas. Verificou-se que os estágios mais avançados dos produtos de alteração de rochas basálticas de São Paulo, representados por latossolo roxo e terra roxa estruturada, apresentavam como componente principal a caulinita e, secundariamente, gibbsita e alofana, além de teores mais baixos de mica e vermiculita

*Seção de Pedologia do Instituto Agronômico do Estado de São Paulo, Campinas, SP, e Pesquisador do Conselho Nacional de Pesquisas

**Seção de Pedologia do Instituto Agronômico de Campinas

***Departamento de Agrotecnia e Geologia da Faculdade de Ciências Médicas e Biológicas de Botucatu 
(Moniz e Jackson, 1967; Escobar et al., 1971; Moniz e Carvalho, 1973). Em áreas onde o processo de dessilicatização foi mais intenso, encontram-se perfis de latossolo roxo no planalto ocidental, como os estudados por Moniz e Jackson (1967), em que o teor de gibbsita se igualava ao de caulinita. Esses autores constataram a seguinte seqüência de intemperismo:

$$
\text { rocha } \longrightarrow \text { mica } \longrightarrow \text { caulinita e alofana } \longrightarrow \text { gibbsita }
$$

Devido aos baixos teores de potássio de tais rochas, o teor de mica secundária formada é muito pequeno. Dessa maneira, grande parte da rocha se altera diretamente para o estágio seguinte da caulinita e alofana.

Recentemente, Melfi e Levi (1971) e Levi e Melfi (1972) estudaram os aspectos geoquímicos do intemperismo, bem como caracterizaram mineralogicamente os primeiros estágios do processo de alteração de diabásio, basalto e gabro. Verificaram que, em condições de boa drenagem, a gibbsita, que se forma nos primeiros estágios de intemperismo de rochas básicas, é o mineral mais abundante. Nos últimos estágios da alteração incipiente, o mineral secundário mais importante é a caulinita. Esse fato não foi considerado por aqueles autores como ressilicatização de gibbsita, como foi sugerido por Paiva Netto e Nascimento (1957), mas o início de uma fase mais intensa do intemperismo, envolvendo outros silicatos primários, como o piroxênio, que produz condições físico-químicas adequadas para a formação de caulinita.

Bates (1962) mostrou a relação que existe entre a precipitação anual, quantidade de lixiviação, remoção de sílica e bases com a natureza dos produtos de intemperismo de rochas basálticas do Havaí. De um modo geral, foram encontradas as seguintes características mineralógicas: (a) minerais do grupo da montmorilonita em áreas secas, onde a lixiviação não removeu todas as bases; $(b)$ haloisita e alofana em áreas com suficiente umidade para permitir lixiviação de bases, mas não toda a sílica; $(c)$ alumina hidratada e géis de $\mathrm{Al}-\mathrm{Fe}$ em áreas permanentemente úmidas, ou com alternância úmida seca e tempo suficiente para permitir remoção da sílica; ou laterita ou gibbsita, se ocorrer em períodos secos.

Nesse trabalho, estudaram-se as duas primeiras camadas de alteração de rochas basálticas de São Paulo. Deu-se ênfase ao estudo da mobilidade dos constituintes das rochas durante a alteração dessas duas camadas e procurou-se caracterizar mineralogicamente esses materiais.

Apesar de se tratar do estudo das duas primeiras camadas de alteração, afastadas poucos milímetros da rocha inalterada, os resultados obtidos não são restritos, como poderia parecer, haja visto que essas camadas chegam a se apresentar extremamente alteradas, abrangendo com isso uma grande variedade de estágios de alteração.

Métodos de campo e de laboratório Os produtos de alteração de rochas basálticas estudados aqui compreendem (a) uma camada denominada rocha alterada, friável, de cor amarelo-brunada, ou bruno-amarelada, separada da rocha inalterada por $(b)$ uma camada denominada rocha semi-alterada, muito delgada, de poucos milímetros de espessura, nem sempre perceptível, com textura e consistência semelhante às da rocha inalterada. Essa camada é visualizada macroscopicamente pela cor mais pálida do que a rocha inalterada.

Realizaram-se ao todo 73 análises químicas de rochas basálticas, sendo 48 inalteradas, 10 semi-alteradas e 15 alteradas, todas procedentes de São Paulo (Tab. I). A localização das amostras semi-alteradas e inalteradas encontra-se na Fig. 1. Como se observa, parte dos materiais foi coletada ao norte do Estado, nos municípios de Barretos, Jardinópolis e Ribeirão Preto, região cujo clima é do tipo Aw, tropical com estação úmida de verão e seca de inverno. $\mathrm{O}$ restante do material alterado e semi-alterado foi coletado ao sul dessa 
região, numa área de clima do tipo Cwa, tropical de altitude, com estação úmida de verão e seca de inverno. A precipitação anual dessas duas regiões vai de 1150 a 1300 mm, com uma variação de $\pm 250 \mathrm{~mm}$.

Tabela I - Relação e localização das amostras de rochas basálticas do Estado de São Paulo

\begin{tabular}{rlrlrl}
\hline Rocha & \multicolumn{1}{c}{ Município } & Rocha & \multicolumn{1}{c}{ Município } & Rocha & Município \\
\hline \hline 1229 & Ribeirão Preto & 168 & São Carlos & 1249 & Limeira \\
1511 & Ribeirão Preto & 180 & Olimpia & 1386 & Sertãozinho \\
1518 & Ribeirão Preto & 308 & Olímpia & 1535 & Laranjal \\
1519 & Ribeirão Preto & 664 & Igarapava & 1536 & Laranjal \\
1876 & Rio Claro & 791 & Caraguatatuba & 1858 & Americana \\
1953 & São Manoel & 799 & Santa Rita do Passa Quatro & 1866 & Laranjal \\
553 & Americana & 845 & Guaíra & 1868 & Laranjal \\
628 & São Manoel & 1024 & Santa Cruz da Conceição & 1869 & Laranjal \\
633 & Jaú & 1044 & Itu & 1870 & Laranjal \\
669 & Jardinópolis & 1051 & Santa Rita do Passa Quatro & 1871 & Laranjal \\
1952 & Jaú & 1064 & Franca & 1872 & Laranjal \\
1955 & Laranjal & 1074 & Patrocínio do Sapucai & 1873 & Laranjal \\
874 & Barretos & 1098 & Ribeirão Preto & 1921 & Brotas \\
1230 & Ribeirão Preto & 1105 & Avaré & 1923 & Campinas \\
1523 & Campinas & 1108 & Icém & 1940 & Torrinha \\
1942 & Jaú & 1116 & Porto Ferreira & 525 & Campinas \\
138 & São Luís de Paraitinga & 1122 & Botucatu & 1867 & Rio Claro \\
\hline
\end{tabular}

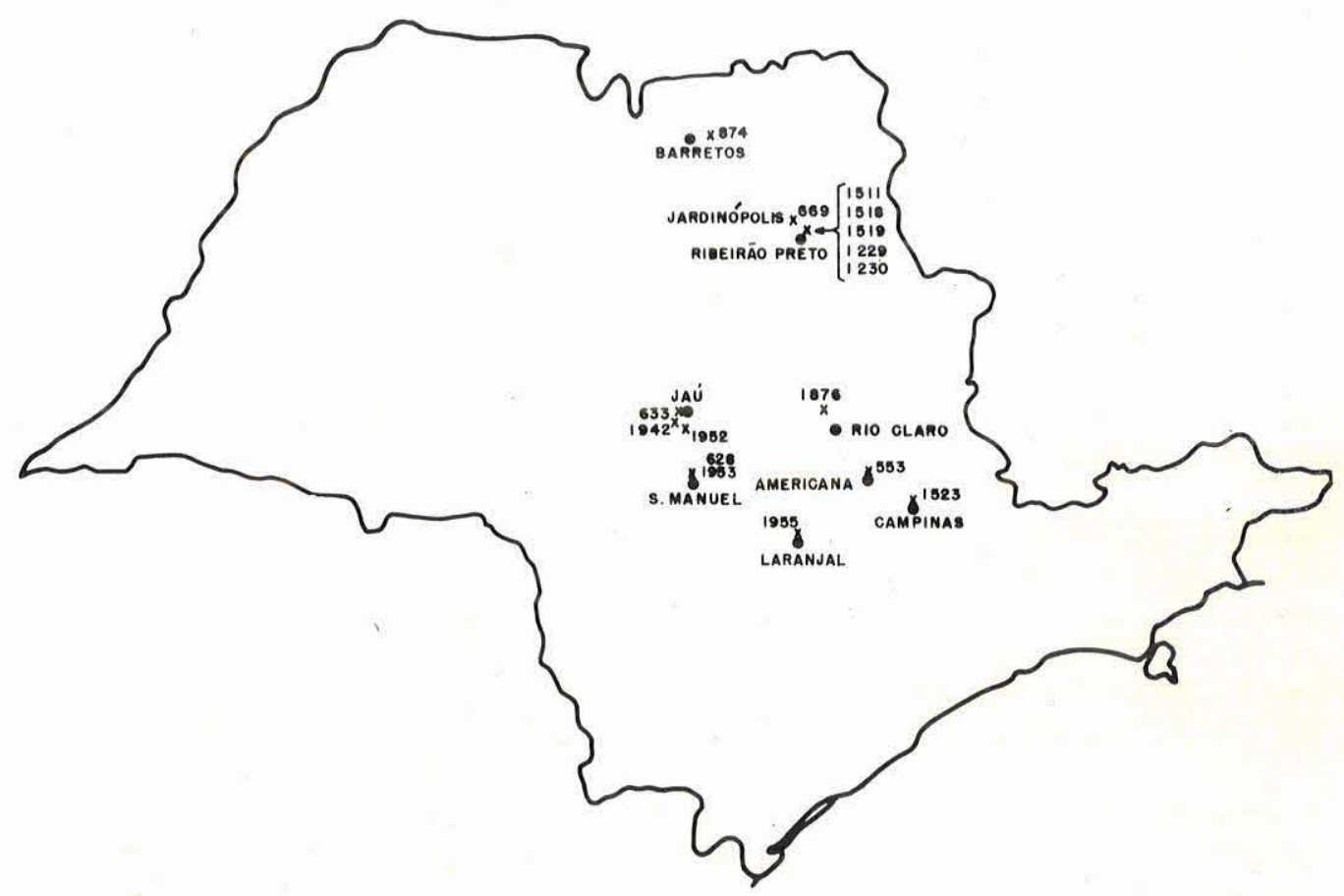

Figura 1 - Mapa do Estado de São Paulo. Estão assinalados os locais de coleta das amostras de rochas basálticas semi-alteradas e alteradas 
MÉTODOS DE LABORATÓRIO Realizaram-se análises químicas de todas as amostras de rochas inalteradas, semi-alteradas e alteradas. Nas determinações mineralógicas das rochas semi-alteradas e alteradas empregaram-se os métodos de difração dos raios X e análise térmica diferencial. Determinou-se a capacidade de troca de catíons das mesmas rochas para auxiliar a interpretação dos dados mineralógicos.

a) Análise química Utilizaram-se os métodos preconizados por Kolthoff e Sandel (1943), com exceção da determinação de sódio e potássio, a qual foi realizada por fotometria de chama. Para a determinação de $\mathrm{SiO}_{2}, \mathrm{Al}_{2} \mathrm{O}_{3}, \mathrm{Fe}_{2} \mathrm{O}_{3}$ total, $\mathrm{TiO}_{2}, \mathrm{P}_{2} \mathrm{O}_{5}, \mathrm{CaO}$ e $\mathrm{MgO}$, fez-se fusão com carbonato de sódio. A sílica foi determinada gravimetricamente depois de desidratada; seu filtrado foi neutralizado com hidróxido de amônia para precipitar ferro, alumínio, titânio e fósforo, e, em seguida, calcinados e pesados os óxidos. Dissolveu-se o precipitado com pirossulfato de sódio para determinação de ferro, titânio e fósforo. O ferro foi determinado volumetricamente com bicromato de potássio e o titânio e o fósforo foram determinados colorimetricamente, respectivamente com peróxido de hidrogênio e com molibdato de amônio, tendo como redutor o ácido ascórbico. $\mathrm{O}$ alumínio foi determinado por diferença. No filtrado do precipitado de hidróxido de amônia, o cálcio foi precipitado com oxalato de amônio e determinado volumetricamente com permanganato de potássio. No filtrado do precipitado de oxalato de cálcio, o magnésio foi determinado com fosfato diamônio.

Em outra amostras, determinaram-se o sódio e o potássio por fotometria de chama, após fluorização.

Outra amostra foi tratada com ácidos fluorídrico e sulfúrico a quente, sendo o ferro ferroso determinado por titulação com permanganato de potássio em presença de ácido bórico.

O dióxido de carbono foi determinado gravimetricamente por absorção em ascarite. A água higroscópica $\left(\mathrm{H}_{2} \mathrm{O}^{-}\right)$foi determinada em estufa, na faixa térmica $105-110^{\circ} \mathrm{C}$. A água combinada $\left(\mathrm{H}_{2} \mathrm{O}^{+}\right)$foi determinada pelo método de Penfield.

b) Difração dos raios $X$ Utilizou-se um difratômetro da Norelco, com radiação de cobre, no estudo das rochas alteradas e semi-alteradas, tendo-se obtido difratogramas de amostras orientadas e em pó. Após aquecimento a $100^{\circ} \mathrm{C}$, as amostras foram reexaminadas, com a finalidade de verificar-se a possível presença de haloisita.

c) Análise térmica diferencial Empregou-se um aparelho Delta Therm, com suporte de quatro canais e termopares de cromel-alumel e velocidade de aquecimento aproximadamente de $10^{\circ} \mathrm{C} / \mathrm{min}$. A finalidade principal foi o estudo dos materiais amorfos.

d) Capacidade de troca de catíons Foi determinada com solução de acetato de amônio normal, pH 7,0, empregando-se a técnica de percolação usada na seção de Pedologia do Instituto Agronômico de Campinas (Paiva Netto et al., 1956).

COMPOSIÇÃO QUÍMICA E MINERALÓGICA Os resultados das 73 análises químicas encontram-se na Tab. II, tendo sido calculada a média para cada elemento a partir de 48 análises de rochas inalteradas, e seus coeficientes de variação. Os valores da média aqui obtidos mostram boa concordância com as médias admitidas para a rocha-tipo na natureza toleítica.

Os produtos de alteração de rochas basálticas de São Paulo, apesar de provirem de camadas muito próximas da rocha inalterada, apresentaram grande variação de 
Tabela II - Análise química de rochas basálticas inalteradas (I), semi-alteradas (SA) e alteradas (A) do Estado de São Paulo

\begin{tabular}{|c|c|c|c|c|c|c|c|c|c|c|c|c|c|c|c|c|}
\hline notha & & $\mathrm{CO}_{2}$ & $2_{3} \mathrm{O}_{3}$ & $2_{2}{ }^{2}$ & 700 & $\mathrm{HgO}_{\mathrm{g}}$ & $\mathrm{CoO}$ & $2^{\circ}$ & $\mathrm{x}_{2} \mathrm{O}$ & $\mathrm{B}_{2} \mathrm{O}^{+}$ & $\mathrm{B}_{2} \mathrm{O}^{-}$ & $\mathrm{HO}_{2}$ & $\infty_{2}$ & $\mathrm{P}_{2} \mathrm{O}_{5}$ & $\operatorname{HenO}$ & \\
\hline $29 \mathrm{~s}$ & & $\begin{array}{l}48,20 \\
34,20 \\
12, \infty\end{array}$ & $\begin{array}{l}17,90 \\
23,60\end{array}$ & $\begin{array}{r}4,90 \\
8,80 \\
29,30\end{array}$ & $\begin{array}{l}9,98 \\
8, \infty \\
2,60\end{array}$ & $\begin{array}{l}5,08 \\
0,94\end{array}$ & & & 0,31 & $\begin{array}{l}6, \infty 0 \\
0,40\end{array}$ & 1, & & & & $\begin{array}{l}0,28 \\
0,20 \\
0,11\end{array}$ & $\begin{array}{l}99,71 \\
99,55\end{array}$ \\
\hline 1521 & & $\begin{array}{r}49,70 \\
41,20 \\
8, \infty 0\end{array}$ & $\begin{array}{l}15,70 \\
13,80\end{array}$ & $\begin{array}{r}3, \infty 0 \\
10,70 \\
33, \infty 0\end{array}$ & $\begin{array}{l}9,80 \\
8,40 \\
3,30\end{array}$ & & & & $\begin{array}{l}0,80 \\
0,40 \\
0,44\end{array}$ & & , & & & & $\begin{array}{l}0,20 \\
0,20 \\
0,05\end{array}$ & $\begin{array}{r}99,88 \\
99,68 \\
100,71\end{array}$ \\
\hline 518 & & $\begin{array}{l}49,60 \\
35,60 \\
18,90\end{array}$ & $\begin{array}{l}14,30 \\
17, \infty \\
19,20\end{array}$ & $\begin{array}{r}3,20 \\
12,40 \\
28,60\end{array}$ & $\begin{array}{r}11, \infty \\
7,90 \\
1,60\end{array}$ & $\begin{array}{l}4,9 \\
0,7\end{array}$ & 0,07 & & & $\begin{array}{r}0,50 \\
6,50 \\
11, \infty 0\end{array}$ & $\begin{array}{r}1, \\
5, \\
12,\end{array}$ & &,$\infty 22$ & & & $\begin{array}{l}00,20 \\
09,60\end{array}$ \\
\hline 1519 si & & $\begin{array}{l}49,20 \\
37,00 \\
19,00\end{array}$ & $\begin{array}{l}4,60 \\
16,30 \\
19,70\end{array}$ & $\begin{array}{r}3,20 \\
11,70 \\
27,50\end{array}$ & $\begin{array}{r}10,70 \\
7,60 \\
1,90\end{array}$ & & 020 & & & & $\begin{array}{c}1, \\
5, \\
4,\end{array}$ & & & & & $\begin{array}{r}99,70 \\
10,54 \\
100,77\end{array}$ \\
\hline 2876 si & & $\begin{array}{l}48, \infty \\
39,80 \\
17, \infty\end{array}$ & $\begin{array}{l}15,10 \\
18,23 \\
24,70\end{array}$ & $\begin{array}{r}4,20 \\
10,90 \\
22,80\end{array}$ & $\begin{array}{l}9,80 \\
5,90 \\
2,50\end{array}$ & & $\begin{array}{l}7,59 \\
5,21 \\
0,92\end{array}$ & & & $\begin{array}{l}1,20 \\
4,34 \\
8,60\end{array}$ & 0 & & & & & $\begin{array}{r}99,70 \\
100,40 \\
99,59\end{array}$ \\
\hline 2953 si & & $\begin{array}{l}49,00 \\
39,40 \\
36, \infty\end{array}$ & $\begin{array}{l}14,36 \\
20,12 \\
20,13\end{array}$ & $\begin{array}{r}4,47 \\
17,36 \\
17,76\end{array}$ & $\begin{array}{l}9,66 \\
3,10 \\
3,10\end{array}$ & $\begin{array}{l}3,83 \\
0,82 \\
1, \infty 0\end{array}$ & $\begin{array}{l}7,83 \\
1,33 \\
0,38\end{array}$ & $\begin{array}{l}2,79 \\
1,05 \\
0,30\end{array}$ & & $\begin{array}{l}1,26 \\
6,00\end{array}$ & & 0 & & & $\begin{array}{l}0,19 \\
0,10 \\
0,10\end{array}$ & $\begin{array}{r}100,3 \% \\
102,56 \\
99,86\end{array}$ \\
\hline 553 & $\begin{array}{l}x \\
A\end{array}$ & $\begin{array}{l}49,20 \\
11,40\end{array}$ & & $\begin{array}{r}4,30 \\
29,20\end{array}$ & $\begin{array}{l}8,90 \\
4,70\end{array}$ & & 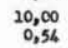 & & & & & & & & & $\begin{array}{l}99,80 \\
99,62\end{array}$ \\
\hline 628 & I 1 & $\begin{array}{l}48,20 \\
19,80\end{array}$ & 14,3 & $\begin{array}{r}6,30 \\
24,55\end{array}$ & $\begin{array}{l}7,80 \\
3,11\end{array}$ & 4,5 & 9,12 & $\begin{array}{l}2,55 \\
0,45\end{array}$ & 1, & $\begin{array}{l}1,75 \\
7,26\end{array}$ & $\begin{array}{c}0, \\
10,\end{array}$ & $\begin{array}{l}3,31 \\
5,70\end{array}$ & $\begin{array}{l}0,01 \\
0,12\end{array}$ & & $\begin{array}{l}0,25 \\
0,11\end{array}$ & $\begin{array}{l}100,18 \\
100,43\end{array}$ \\
\hline 6331 & $\begin{array}{l}1 \\
4\end{array}$ & 49, &  & 8 & $\begin{array}{l}8,70 \\
2,40\end{array}$ & & & & & & & 7,80 & $\overline{0,0 / 4}$ & & 16 & $\begin{array}{l}99,90 \\
99,77\end{array}$ \\
\hline 669 & I & $\begin{array}{l}50,60 \\
17,80\end{array}$ & $\begin{array}{l}13, \infty 0 \\
20,01\end{array}$ & $\begin{array}{r}7,10 \\
23,35\end{array}$ & $\begin{array}{l}7,80 \\
3,71\end{array}$ & $\begin{array}{l}3,74 \\
0,90\end{array}$ & $\begin{array}{l}7,22 \\
0,68\end{array}$ & $\begin{array}{l}2,98 \\
0,51\end{array}$ & $\begin{array}{l}2,83 \\
0,79\end{array}$ & $\begin{array}{l}1,20 \\
4,30\end{array}$ & $\begin{array}{l}1, \infty \\
15, \infty\end{array}$ & $\begin{array}{l}2,90 \\
4,30\end{array}$ & $\begin{array}{l}0, \infty \\
0,10\end{array}$ & $\begin{array}{l}0,33 \\
0,59\end{array}$ & $\begin{array}{l}0,20 \\
0,03\end{array}$ & $\begin{array}{l}100, \infty \\
100,47\end{array}$ \\
\hline 1952 & $\begin{array}{l}1 \\
1\end{array}$ & $\begin{array}{l}48,40 \\
28,20\end{array}$ & & & $\begin{array}{l}9,35 \\
4,83\end{array}$ & & & & & & & & & & 24 & 90,84 \\
\hline 2955 & I & $\begin{array}{l}47,80 \\
32,80\end{array}$ & & $\begin{array}{r}3,80 \\
18,10\end{array}$ & $\begin{array}{r}10,28 \\
2,80\end{array}$ & $\begin{array}{l}3,3 \\
1,2\end{array}$ & 0,5 & $\begin{array}{l}2,79 \\
0,42\end{array}$ & & & & $\begin{array}{l}3,50 \\
4,85\end{array}$ & & & 39 & $\begin{array}{r}99,35 \\
100,04\end{array}$ \\
\hline 874 & & $\begin{array}{l}47,80 \\
40, \infty\end{array}$ & 2,87 & $\begin{array}{r}7,07 \\
10,23\end{array}$ & $\begin{array}{l}7,32 \\
5,74\end{array}$ & 4,8 & $\begin{array}{l}9,7 \\
6,7\end{array}$ & $\begin{array}{l}2,60 \\
1,42\end{array}$ & & & 0,8 & $\begin{array}{l}3,00 \\
3,40\end{array}$ & $\begin{array}{l}0, \infty \\
0, \infty, 4\end{array}$ & $\begin{array}{l}0,33 \\
0,33\end{array}$ & 18 & $\begin{array}{r}99,89 \\
100,37\end{array}$ \\
\hline $1230 \mathrm{gr}$ & & 26, & & & $\begin{array}{l}7,50 \\
2,50\end{array}$ & & & & & & & & $0, \overline{10}$ & & 20 & $\begin{array}{l}0,30 \\
0,25\end{array}$ \\
\hline $1523 \mathrm{si}$ & A & $\begin{array}{l}44,20 \\
30,60\end{array}$ & $\begin{array}{l}14,40 \\
18,60\end{array}$ & $\begin{array}{l}13,50 \\
27,80\end{array}$ & $\begin{array}{l}5,60 \\
3,40\end{array}$ & 4,1 & $\begin{array}{l}7,2 \\
0,6\end{array}$ & $\begin{array}{l}1,40 \\
0,14\end{array}$ & 0,16 & & $\begin{array}{l}2,50 \\
7,10\end{array}$ & & in & & , 03 & $\begin{array}{l}99,71 \\
99,94\end{array}$ \\
\hline $2942 \mathrm{st}$ & 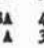 & $\begin{array}{l}42,20 \\
31,60\end{array}$ & 14. & $\begin{array}{l}10,80 \\
19,19\end{array}$ & $\begin{array}{l}6,17 \\
1,09\end{array}$ & 4, & & $\begin{array}{l}1,74 \\
0,40\end{array}$ & $\begin{array}{l}1,20 \\
0,11\end{array}$ & $\begin{array}{l}1,7 \\
10,9\end{array}$ & 1 & & $0, \alpha_{4}$ & & , 20 & $\begin{array}{r}99,57 \\
100,45\end{array}$ \\
\hline 138 & I & 49,80 & 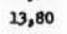 & 3,10 & 10,00 & & 7,9 & 2,85 & 2,10 & 0,90 & 3 & 4,20 & 0,01 & 0,59 & 24 & 99,68 \\
\hline 168 & I & 50,20 & 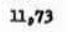 & 6,90 & $9, \infty$ & 2 & 8. & 2,79 & 1,5 & 1,25 & $0, ?$ & 3,90 & 01 & 0,57 & 20 & $100, \infty$ \\
\hline 180 & I & 48,40 & 12 & 8,30 & 7,80 & 4,2 & 9 & 2,34 & 0,9 & 0,90 & 1,0 & 3,00 & $\infty$ & 0,40 & 20 & 99,51 \\
\hline 306 & $I 5$ & 51,00 & 2,63 & 5,00 & 9,19 & 3,9 & 7,9 & 2,98 & 2,00 & 1,00 & 0,5 & 3,50 & 12 & 0,47 & 25 & 100,45 \\
\hline 664 & I & 50,40 & 1,30 & 5,80 & 9,40 & 3,8 & $6,5:$ & 3,30 & 1,59 & 1,00 & 1,2 & 3,90 & 102 & 0,60 & 20 & 99,29 \\
\hline 791 & 14 & 48,00 & 20 & 5,60 & 7,60 & $3 x$ & 7 & 3,51 & 2,4 & 0,80 & 1, & $4, \infty$ & $\mathbb{Q}$ & 0,92 & 16 & 99,62 \\
\hline 799 & I & 49,80 & ( & 6,80 & $7, \infty$ & 4.29 & 86 & 2,60 & 1,37 & 0,15 & 12 & 2,70 & $\infty$ & 0,45 & 17 & 99,46 \\
\hline 845 & I & 49,50 & 3,45 & 0,10 & 4,74 & 4 & 8 , & 2,80 & 16 & 36 & 0,8 & 2,47 & $x$ & 0,36 & 19 & 100,90 \\
\hline 1024 & I & 49,40 & 1) & 80 & 9,00 &  & & 2340 & & & , & 200 & 05 & 0,45 & 19 & 99,28 \\
\hline 1044 & I & 47,40 & 8 & 10 & 5,90 & . & 7, & 3,07 & 2,20 & 20 & 0,80 & 2,30 & 03 & 0,55 & 0,13 & 100,08 \\
\hline 1051 & 14 & 47,80 & & n & 10,90 & & & & 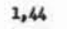 & & & & $\infty$ & 0,36 & 0,19 & 99,96 \\
\hline 1064 & I 4 & $48, \infty$ & & 30 & 10,90 & t & & & 1,7 & & & 6 & ,03 & 0 , & 22 & 100,47 \\
\hline 1074 & 14 & 48,80 & & & 8,80 & & & & & & & 3 & $\infty$ & 0 , & 0,22 & 100,30 \\
\hline 1096 & 14 & 49,60 & & & 8,72 & & & & & & & 70 & $\infty$ & 0,45 & 19 & 70 \\
\hline$n 105$ & 14 & $49, \infty$ & 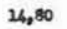 & & 9,50 & 3,50 & & & Gs & & & 31 & $0, \boldsymbol{m}$ & 0,67 & 31 & 100,20 \\
\hline 1108 & I 4 & 49,80 & 3.0 & . & 8,18 & 5 & & $\infty$ & 8. & & & 2,9 & - & 0 , & 22 & 100,51 \\
\hline 11116 & 15 & 50,40 & 3,60 & & 9,00 & 2, & 0,3 & $\infty$ & & & & 2,40 & $\alpha$ & 0,92 & 0,30 & 99,51 \\
\hline 1122 & I & $47, \infty$ & 0 & 33 & $9, \propto$ & 4,58 & 8,40 & 3,16 & 1,69 & 1,24 & 0,30 & $4, \infty$ & $\infty$ & 0,55 & 0,19 & 100,05 \\
\hline 2249 & $T$ & $49, \infty$ & & & 9,20 & $4, \infty$ & & 3,75 & 2.90 & & & 2,40 & , & 0,66 & 31 & 99,52 \\
\hline 1386 & I & $47, \infty$ & (a) & S & 8,70 & 4,5 & & & ביר & & & 3,70 & $\infty 2$ & 0,47 & 0,29 & 100,21 \\
\hline 1535 & Is & 50,0 & & 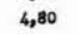 & 8,10 & 5, & t & & 20 & & & 3. & $\alpha$ & 0 & 24 & $100, \infty 2$ \\
\hline 1536 & 15 & $51, \infty$ & 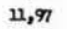 & 6,22 & 8,26 & 4,2 & 6,43 & 3,26 & & $2 y=x$ & . & 3,30 & os & 0,83 & 23 & 99,76 \\
\hline 1858 & I 4 & 48,00 & 1,40 & 3,90 & $111, \infty$ & 4,50 & 9,54 & 2,55 & 1,20 & 0,50 & 1,62 & 3,60 & , o4 & 0,33 & ,30 & 100,48 \\
\hline 1866 & 14 & 47,90 & & 4,14 & 11,22 & 4,66 & & & 1,35 & & & 3,50 & ,03 & 0,40 & 22 & 99,62 \\
\hline 2868 & I 4 & 48,90 & & & 8,26 & 3, & & & 36 & & & 3 & 36 & 0 & 22 & 99,79 \\
\hline 1869 & I 4 & 47,80 & & 6,3 & 9,19 & 40 & 10, & & 1, & & & 3, & 60 & 0,38 & 22 & 100,20 \\
\hline 1870 & 15 & 50,60 & 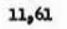 & 6,80 & 8,10 & 3,73 & 7,40 & 3,16 & 1,92 & 1,76 & 0,42 & 2,90 & 0,33 & 0,69 & 0,25 & 99,67 \\
\hline 2871 & $I 4$ & 48,60 & 2,33 & 8,00 & 7,20 & 4,62 & 5,07 & 3,44 & $2,1 / 4$ & 2,46 & $2, \infty$ & 2,40 & 0,90 & 0,87 & 0,21 & 100,24 \\
\hline 1872 & I 4 & 49,60 & $n$ & 7,90 & 5,70 & 3,35 & & 3,35 & 1,49 & 1,00 & & 3,00 & 0,18 & 0,43 &, 18 & 99,21 \\
\hline 1873 & I & 49,20 & 2,87 & 8,00 & 7,00 & 4, & & $3, \infty$ & 1,47 & & & 3,30 & 0,34 & 0,43 & 0,18 & 100,28 \\
\hline 1921 & I & 48,80 & & . & 0,10 & 5, & & & & & & 3,80 & $0, \infty$ & 0,47 & 0,22 & 100,42 \\
\hline 1923 & 4 & 46,80 & 14,8 & 3,20 & 11,50 & 5,9 & $n$ & 2,51 & 1,10 & pe & 0,60 & 3,20 & 0,04 & 0,57 & 0,27 & 100,29 \\
\hline 1940 & $\underline{\underline{I}}$ & & & & & & & & & & & & & & & \\
\hline 525 & $=$ & & 23,70 & & $9, \infty$ & 4,90 & on & 2,30 & & & & & 0,02 & 0,40 & 0,20 & \\
\hline 1867 & I & 47,80 & $12, \infty 0$ & 6,34 & 8,98 & 4,99 & 9,52 & 2,56 & 1,30 & 1,74 & 0,30 & 3,50 & 0,16 & 0,40 & 0,21 & 99,80 \\
\hline & & 43,8 & . & & 8,83 & 4,37 & 8,27 & 2,80 & 1,51 & 1,18 & 0,89 & 3,27 & 0,09 & 0,51 & 0,22 & \\
\hline c. & 1 & & 11,0 & 28,6 & 16,7 & 7,9 & 23,4 & 13,6 & 29,8 & 53,7 & 54,6 & 26,4 & $\infty, 2$ & 30,6 & 1,90 & \\
\hline
\end{tabular}


composição química, como se pode avaliar através da relação molecular sílica/alumina (Tab. III). Como se observa, a camada alterada apresentou valores de Ki inferiores aos da camada semi-alterada, o que evidencia seu maior grau de alteração. É interessante notar a grande variação na composição química da camada alterada, refletida pelos valores de $\mathrm{Ki}$, que vão desde 0,49 até 3,33 . A camada semi-alterada também varia bastante, embora menos que a anterior, num intervalo de 3,25 a 5,22. A rocha inalterada apresentou valores acima de 5,13, chegando até 6,62 .

Tabela III - Relação molecular sílica/alumínio (Ki) de rochas basálticas inalteradas, semi-alteradas e alteradas

\begin{tabular}{rccc}
\hline Rocha & Inalterada & Semi-alterada & Alterada \\
\hline 1511 & 5,38 & 5,07 & 0,49 \\
553 & 5,69 & - & 0,76 \\
1229 & 5,54 & 3,25 & 0,86 \\
1876 & 5,40 & 3,71 & 1,17 \\
628 & 5,73 & - & 1,28 \\
669 & 6,62 & - & 1,51 \\
1519 & 5,73 & 3,86 & 1,64 \\
1518 & 5,90 & 3,56 & 1,67 \\
1230 & - & 4,27 & 2,06 \\
1942 & - & 4,85 & 2,52 \\
1955 & 5,13 & - & 2,76 \\
1523 & - & 5,22 & 2,80 \\
1953 & 5,80 & 3,33 & 3,04 \\
1952 & 6,40 & - & 3,13 \\
633 & 6,21 & - & 3,33 \\
874 & 6,31 & 3,60 & - \\
\hline
\end{tabular}

Tabela IV - Valores de capacidade de troca de catíons de rocha basáltica semi-alterada e alterada

\begin{tabular}{rcc}
\hline Rocha & $\begin{array}{c}\text { Semi-alterada } \\
(\text { e. mg/100 g) }\end{array}$ & $\begin{array}{c}\text { Alterada } \\
\text { (e. } \mathrm{mg} / 100 \mathrm{~g})\end{array}$ \\
\hline \hline 1511 & 14,00 & - \\
553 & - & 4,20 \\
1229 & 21,00 & 25,60 \\
1876 & 23,20 & 33,60 \\
628 & - & 14,20 \\
669 & - & 14,20 \\
1519 & 23,40 & 32,00 \\
1518 & 30,20 & 45,20 \\
1230 & 21,80 & - \\
1942 & 16,80 & 35,60 \\
1955 & - & 33,40 \\
1523 & 11,20 & 19,40 \\
1953 & 26,80 & 32,20 \\
1952 & - & 25,40 \\
633 & - & 23,80 \\
874 & 18,00 & - \\
\hline
\end{tabular}

Como os materiais estudados foram coletados em locais de boa drenagem e sob uma precipitação anual semelhante, seria de supor que rochas estivessem sujeitas a uma lixiviação semelhante. A grande variação encontrada na remoção de sílica e bases deve-se possivelmente a uma situação local, em que a remoção de sílica não foi favorecida, resultando na formação de materiais menos intemperizados, ou, então, a uma variação do período de tempo que a rocha esteve sujeita a alteração.

A análise mineralógica realizada não foi suficiente para explicar completamente a composição dos produtos de alteração. O exame com difração dos raios X das duas camadas não se mostrou muito profícuo: nenhum argilo-mineral foi identificado, já que, nas regiões de 7,2, 10 e $14 \AA$, nenhum pico apareceu. Quando ocorria a banda, sua intensidade era tão pequena que não permitia verificar qualquer alteração com tratamentos térmicos. A ausência de argilo-minerais é um indício da presença de material muito mal-cristalizado e/ou amorfo. Na Fig. 2, selecionaram-se alguns difratogramas de rochas alteradas, colocadas em ordem crescente de valores de $\mathrm{Ki}$, portanto numa escala decrescente de alteração. Como se pode observar, os únicos minerais secundários identificados inequivocamente foram a gibbsita, nas amostras 1511, 1229 e 669, e a goethita, nas amostras 1511 e 1229 . O único mineral primário identificado foi a magnetita. Como esse mineral possui um espaçamento basal de $2,53 \AA$, valor muito próximo a $2,51 \AA$ da hematita, repetiu-se a análise com difração dos raios $\mathrm{X}$ após remoção do material magnético, tendo desaparecido os espaçamentos 2,53 e 2,97 $\AA$, o que confirmou tratar-se de magnetita. No restante das amostras, de materiais menos intemperizados, não se identificou nenhuma fase cristalina, apesar da presença de alguns máximos difratados. 
Figura 2 - Difratogramas de rochas basálticas alteradas, em ordem crescente de valores de $\mathrm{Ki}$; Gib., gibbsita; Goet., goetita; Mag., magnetita

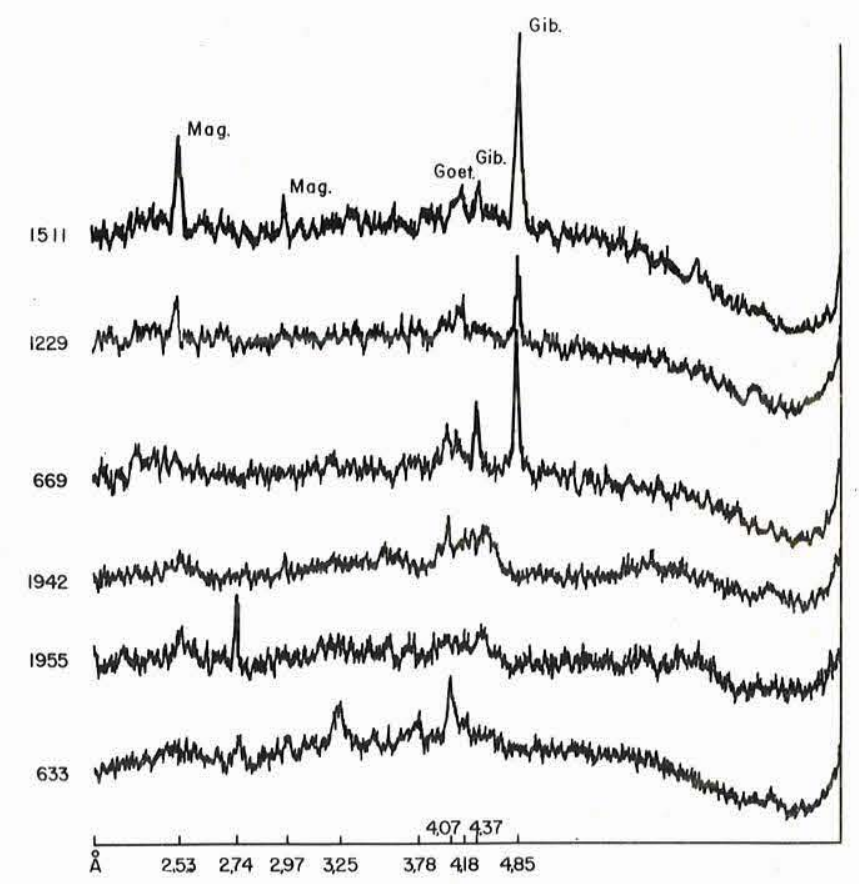

Picos endotérmicos a $120^{\circ} \mathrm{C}$, de grande intensidade, revelados por termogramas (Fig. 3), parecem ser devidos à presença de material amorfo, visto não se ter identificado haloisita nem argilominerais do tipo 2:1 nas análises com difração dos raios X. Esses picos endotérmicos, de baixa temperatura, ocorrem praticamente em todas as amostras de rochas alteradas e, portanto, independem do seu estágio de alteração. Embora não se possa assegurar que se trate do mesmo tipo de material, deve-se mencionar que Melfi e Franco (1971) verificaram que géis amorfos se formavam nos primeiros estágios de alteração do plagioclásio de rochas básicas, e que, em condições de má drenagem esses géis são bem estáveis. Em condições de boa drenagem, a formação incipiente dos géis é acompanhada pela síntese de gibbsita, primeiro mineral formado pela alteração do feldspato. Esses resultados estão de acordo com o esquema apresentado por Valenton (1972) para a alteração de tectossilicatos: inicialmente ocorre uma solubilização, seguindo-se formação de géis de $\mathrm{Al}-\mathrm{Fe}$, gel de $\mathrm{Al}$ e gibbsita.

Os valores relativamente altos da capacidade de troca de catíons, da rocha alterada e semi-alterada, sugerem que os géis amorfos apresentam composição, pelo menos em parte, correspondente à de argilominerais do tipo 2:1 (Tab. IV). Deve-se mencionar, contudo, que alguns termogramas, como os das rochas alteradas 1942, 1955 e 633 (Fig. 3), apresentam picos endotérmicos a $570^{\circ} \mathrm{C}$, que, pela sua grande intensidade, poderiam ser mais devidos à presença de haloisita ou caulinita do que minerais do tipo $2: 1$. Essa possibilidade não exclui, contudo, a possibilidade de ocorrer uma mistura de materiais. Qualquer uma dessas possibilidades, todavia, não pode ser confirmada pela análise com difração dos raios X (Fig. 2).

Metade das amostras de rochas alteradas (Tab. III) apresenta valores de Ki inferior a 2, sendo 0,49 o menor valor. A gibbsita é um dos principais constituintes desses materiais, como foi revelado pelas análises com difração dos raios X (Fig. 2). No exame com análise térmica diferencial, a gibbsita ficou bem caracterizada pela presença do pico endotérmico a $320^{\circ} \mathrm{C}$, como nas rochas alteradas 1511,1229 e 669 (Fig. 3). Esses resultados estão de 


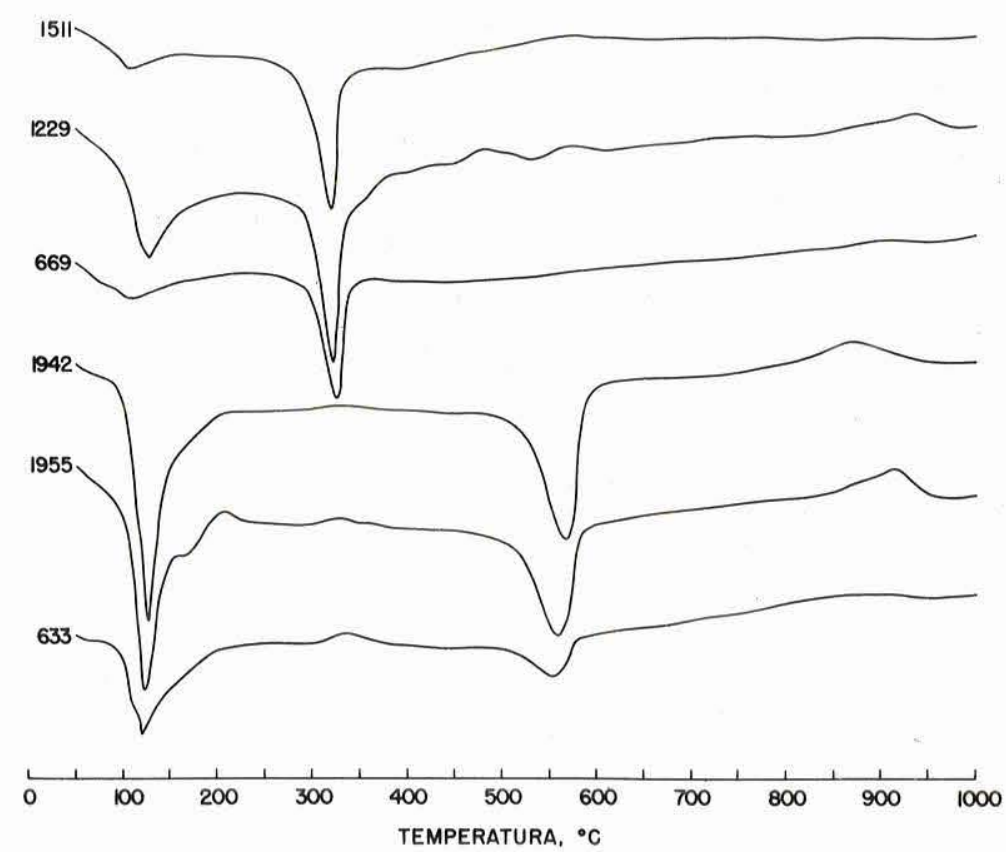

Figura 3 - Termogramas de rochas basálticas alteradas 1511, 1229, 669, 1942, 1955 e 633, em ordem crescente de valores de $\mathrm{Ki}$, respectivamente, 0,$49 ; 0,86 ; 1,51 ; 2,52 ; 2,76$ e 3,33

acordo com os dados de Melfi e Franco (1971), que verificaram ser a gibbsita o mineral mais abundante formado nos primeiros estágios de intemperismo de rochas básicas e anfibolitos, em condições de boa drenagem.

MOBILIDADE DOS CONSTITUINTES Para avaliar a mobilidade relativa dos constituintes de rochas basálticas durante o intemperismo, em condições de boa drenagem, determinou-se quanto eles foram removidos ou concentrados, com base nos dados químicos da Tab. I. Para isso, tomou-se por base a suposição comumente usada de que os teores de alumínio (Krauskopt, 1967) e de titânio (Harrison, 1933) não mudam apreciavelmente durante o intemperismo. A composição química da rocha inalterada tomada como referência para esses cálculos foi: (a) da própria rocha inalterada, de onde se extraíram as camadas semi-alteradas e alteradas, e (b) média de 48 análises químicas de rochas inalteradas do Estado de São Paulo (Tab. I).

Quando se utilizou o método do isotitânio para cálculo da remoção e/ou concentração dos elementos tomando-se como base a análise da própria rocha inalterada, obtiveram-se valores de coeficiente de correlação significativos a $1 \%$ para 7 constituintes: $\mathrm{SiO}_{2}$, $\mathrm{Al}_{2} \mathrm{O}_{3}, \mathrm{MgO}, \mathrm{Na}_{2} \mathrm{O}, \mathrm{MnO}, \mathrm{K}_{2} \mathrm{O}$ e $\mathrm{CaO}$ e a $5 \%$ para $\mathrm{Fe}_{2} \mathrm{O}_{3}$ (Tab. V).

Quando se utilizou, com o mesmo fim, o método do isoalumínio, ainda com base na análise da rocha inalterada, os valores da remoção de potássio deixaram de apresentar valores de coeficientes significativos e o valor do coeficiente encontrado para o sódio deixou de ser significativo a $1 \%$, passando para $5 \%$.

Nos cálculos efetuados com o método do isotitânio tomando-se como referência a média de 48 amostras de rochas inalteradas, verificou-se que o $\mathrm{MnO}, \mathrm{K}_{2} \mathrm{O}$ e $\mathrm{Fe}_{2} \mathrm{O}_{3}$ deixaram de apresentar coeficientes com valores significativos. Ao utilizar o método do 
Tabela V - Valores de coeficiente de correlação entre a porcentagem de remoção e/ou concentração dos constituintes de rochas basálticas semi-alteradas e alteradas e o indice: $\mathrm{Al}_{2} \mathrm{O}_{3}$ (ou $\mathrm{TiO}_{2}$ ) de rocha inalterada/ $\mathrm{Al}_{2} \mathrm{O}_{3}$ (ou $\mathrm{TiO}$ ) da rocha semi-alterada ou alterada

\begin{tabular}{|c|c|c|c|c|}
\hline \multirow{3}{*}{ Constituinte } & \multicolumn{4}{|c|}{ Cálculo do índice baseado } \\
\hline & \multicolumn{2}{|c|}{ Análise de rocha inalterada } & \multicolumn{2}{|c|}{ Média de 48 amostras } \\
\hline & Isotitânio & Isoalumínio & Isotitânio & Isoaluminio \\
\hline $\mathrm{SiO}_{2}$ & $0,883^{* *}$ & $0,835^{* *}$ & $0,881^{* *}$ & $0,879^{* *}$ \\
\hline $\mathrm{Al}_{2} \mathrm{O}_{3}$ & $0,803^{* *}$ & - & $0,716 * *$ & - \\
\hline $\mathrm{MgO}$ & $0,733^{* *}$ & $0,625^{* *}$ & $0,861 * *$ & $0,692^{* *}$ \\
\hline $\mathrm{Na}_{2} \mathrm{O}$ & $0,732 * *$ & $0,520^{*}$ & $0,754^{* *}$ & $0,661^{* *}$ \\
\hline $\mathrm{MnO}$ & $0,675^{* *}$ & $0,620^{* *}$ & 0,233 n.s. & $0,672^{* *}$ \\
\hline $\mathrm{K}_{2} \mathrm{O}$ & $0,666^{* *}$ & 0,177 n.s. & 0,244 n.s. & 0,232 n.s. \\
\hline $\mathrm{CaO}$ & $0,658^{* *}$ & $0,595^{* *}$ & $0,829 * *$ & $0,720^{* *}$ \\
\hline $\mathrm{Fe}_{2} \mathrm{O}_{3}$ & $0,488^{*}$ & 0,102 n.s. & 0,371 n.s. & 0,360 n.s. \\
\hline $\mathrm{P}_{2} \mathrm{O}_{5}$ & 0,337 n.s. & 0,140 n.s. & 0,167 n.s. & 0,375 n.s. \\
\hline $\mathrm{CO}_{2}$ & $-0,312$ n.s. & $-0,373$ n.s. & $-0,056$ n.s. & $-0,392$ n.s. \\
\hline $\mathrm{H}_{2} \mathrm{O}^{+}$ & 0,141 n.s. & 0,376 n.s. & 0,305 n.s. & $-0,028$ n.s. \\
\hline $\mathrm{H}_{2} \mathrm{O}^{-}$ & 0,049 n.s. & $-0,153$ n.s. & $-0,135$ n.s. & $-0,548^{* *}$ \\
\hline $\mathrm{TiO}_{2}$ & - & 0,309 n.s. & - & 0,353 n.s. \\
\hline
\end{tabular}

*Significativo a $5 \%$

**Significativo a $1 \%$

n.s., não significativo

isoalumínio, obteve-se melhor resultado: o $\mathrm{MnO}$ e $\mathrm{H}_{2} \mathrm{O}^{-}$passaram a apresentar valores significativos a $1 \%$, permanecendo o $\mathrm{K}$ sem ser significativo.

Pelos resultados obtidos, pode-se concluir que, para o cálculo da remoção do silício, é possível aplicar-se indistintamente o método do isotitânio ou isoalumínio, assim como se pode tomar como referência a composição química da própria rocha ou a média de 48 análises. $\mathrm{O}$ valor do coeficiente de variação do $\mathrm{SiO}_{2}, 2,3 \%$, foi o menor encontrado, o que mostra a pequena variação de sua composição em diferentes espécimes de rochas basálticas, e possibilita a utilização do seu valor médio para os cálculos de remoção e/ou concentração. $\mathrm{O} \mathrm{Al}_{2} \mathrm{O}_{3}$ também apresentou pequeno coeficiente de variação, podendo-se da mesma forma utilizar como referência a sua média. Com relação a esse elemento, verificou-se uma remoção e concentração de $-60 \% a+40 \%$, respectivamente, que apesar de apresentar grande variação não impediu que o cálculo do isoalumínio apresentasse valores semelhantes aos obtidos com o método do isotitânio.

Dos elementos alcalinos ou alcalino-terrosos - sódio, cálcio e magnésio - que apresentaram os menores valores dos coeficientes de variação, todos apresentaram coeficientes de correlação significativos, quer utilizando o método do isoalumínio, quer do isotitânio com referência à análise da própria rocha ou à média de 48 análises. Já o potássio, que apresentou o maior coeficiente de variação desse grupo de elementos, só apresentou valor significativo do coeficiente de variação quando calculado pelo método do isotitânio e com referência à análise da própria rocha, a exemplo do que aconteceu com o ferro. Os demais constituintes, com os maiores valores de coeficientes de variação, não apresentaram coeficiente de correlação significativos, com exceção da $\mathrm{H}_{2} \mathrm{O}^{-}$, quando calculada pelo método do isoalumínio e com base na média de 48 amostras, apesar do coeficiente de variação ser da ordem de $54,6 \%$.

Se se tomar como referência o número de elementos com valores de coeficiente de correlação significativos, encontrados na Tab. V, conclui-se que o método do isotitânio, 
utilizando a análise da própria rocha inalterada, apresentou os melhores resultados para os materiais estudados, enquanto que o método do isoalumínio seria o recomendado para cálculos de remoção e/ou concentração baseados na média de 48 análises. Por esse motivo, selecionaram-se para apresentação mais detalhada nesse trabalho, as porcentagens de remoção e/ou concentração calculadas pelo método do isotitânio, tomando como referência a análise da própria rocha, estando os elementos arranjados segundo ordem decrescente dos valores do coeficiente de correlação (Figs. 4, 5, 6). Normalmente a remoção dos elementos das rochas semi-alteradas é inferior à da alterada.

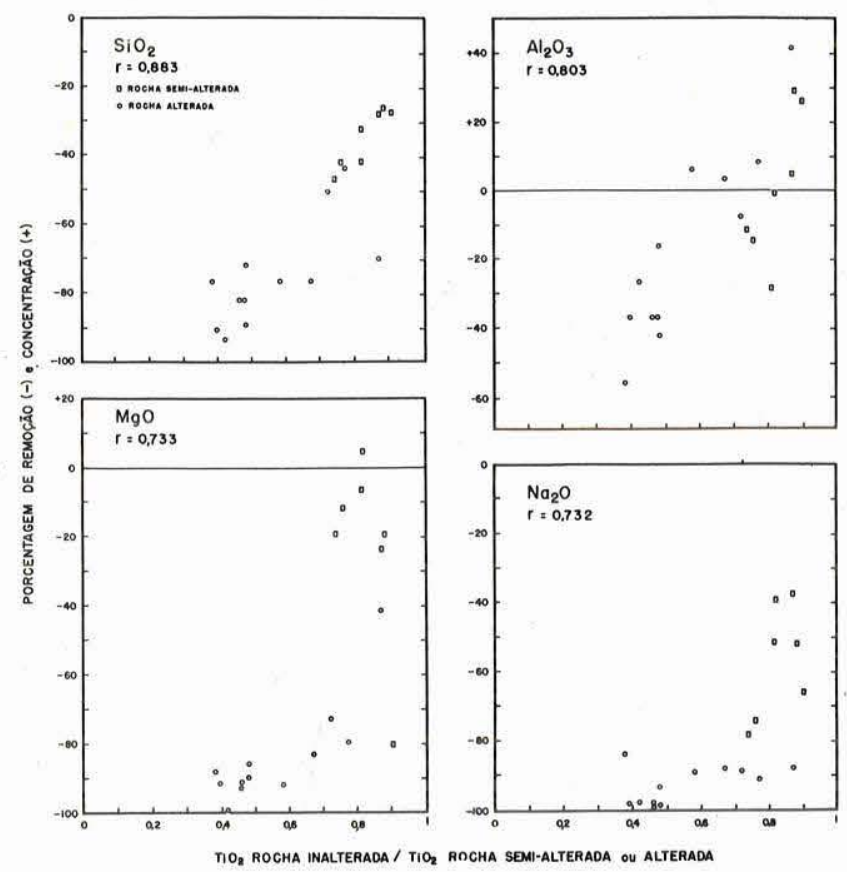

Figura 4 - Gráficos de remoção e concentração de $\mathrm{SiO}_{2}, \mathrm{Al}_{2} \mathrm{O}_{3}$, $\mathrm{MgO}$ e $\mathrm{Na}_{2} \mathrm{O}$ de rochas basálticas semi-alteradas e alteradas, calculadas pelo método do isotitânio, com base na análise da própria rocha

Ciom a finalidade de permitir melhor comparação dos resultados obtidos, calcularam-se as médias de remoção e/ou concentração de cada elemento para cada um dos métodos empregados, tanto para a rocha alterada como para a semi-alterada (Tabs. VI, VII). Os resultados obtidos em cada tabela são bem semelhantes para muitos elementos, qualquer que seja o método empregado. A ordem de remoção e de concentração em cada tabela também é semelhante, qualquer que seja o método empregado.

Tomando-se como referência os valores da média para rochas alteradas e semi-alteradas calculados a partir dos dados obtidos, pelo método do isotitânio, com base na análise da própria rocha (Tabs. VI, VII), verificou-se que ocorreu concentração, em ordem crescente, de $\mathrm{Fe}_{2} \mathrm{O}_{3}, \mathrm{TiO}_{2}, \mathrm{CO}_{2}, \mathrm{H}_{2} \mathrm{O}^{+}$e $\mathrm{H}_{2} \mathrm{O}^{-}$. Todos os outros elementos restantes apresentaram remoção, inclusive $\mathrm{o} \mathrm{Al}_{2} \mathrm{O}_{3}$, cuja remoção se intensifica nos estágios de maior alteração (Fig. 4).

Quando se considera o conjunto de dados obtidos, verifica-se que, para um mesmo elemento, como o ferro (Fig. 5) e o alumínio (Fig. 4), tanto pode ocorrer remoção como concentração, dependendo do estágio de alteração da rocha. Em outros elementos, como o magnésio (Fig. 4), manganês e potássio (Fig. 5) e fósforo (Fig. 6), predomina a remoção do elemento, ocorrendo a concentração apenas em um número muito pequeno de amostras. Com o dióxido de carbono ocorreu o oposto, pois a grande maioria das amostras apresentou concentração, e umas poucas apresentaram remoção (Fig. 6). 
Figura 5 - Gráficos de remoção e concentração de $\mathrm{MnO}, \mathrm{K}_{2} \mathrm{O}$, $\mathrm{CaO}$ e $\mathrm{Fe}_{2} \mathrm{O}_{3}$ de rochas basálticas semi-alteradas e alteradas, calculadas pelo método do isotitânio, com base na análise da própria rocha
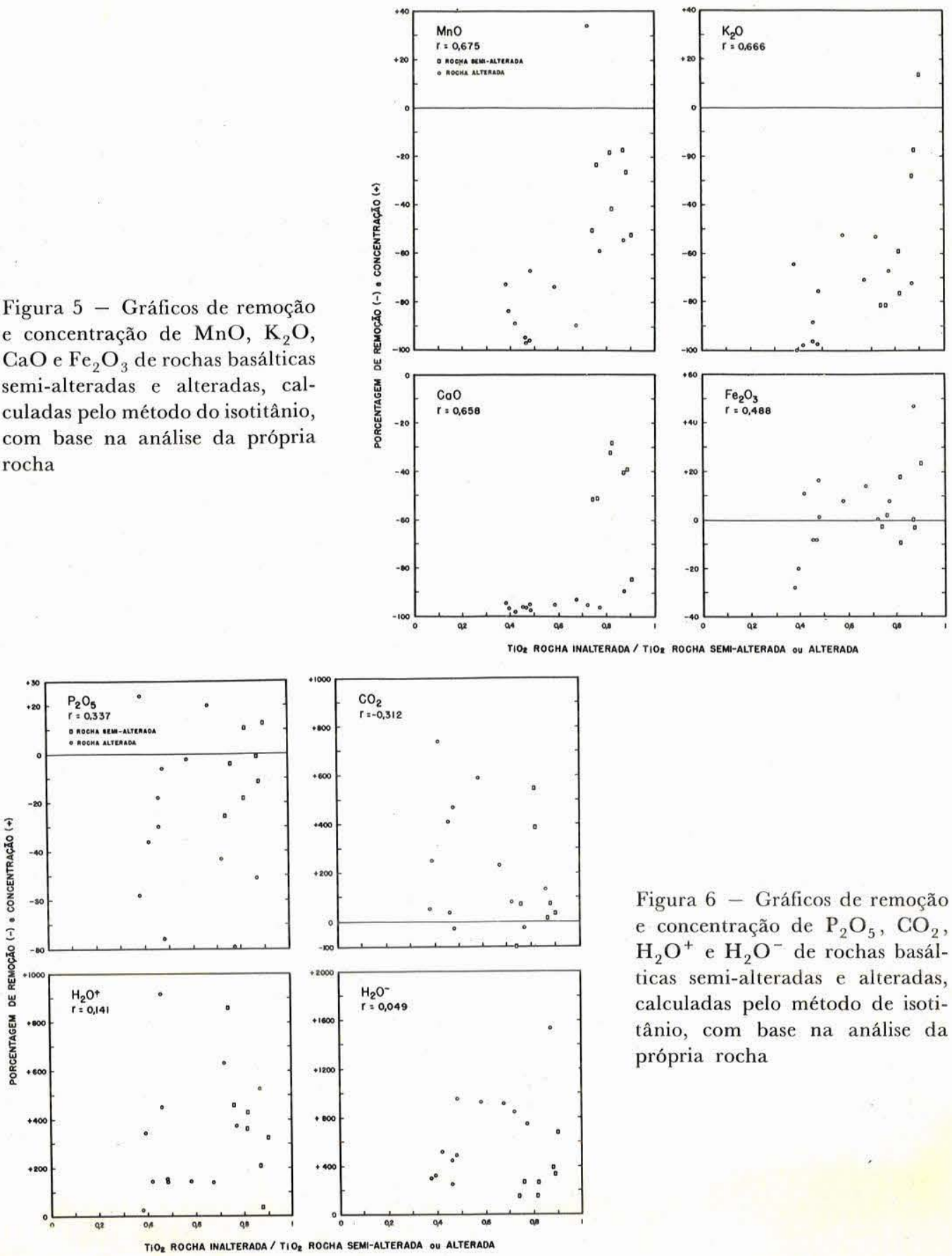

Figura 6 - Gráficos de remoção e concentração de $\mathrm{P}_{2} \mathrm{O}_{5}, \mathrm{CO}_{2}$, $\mathrm{H}_{2} \mathrm{O}^{+}$e $\mathrm{H}_{2} \mathrm{O}^{-}$de rochas basálticas semi-alteradas e alteradas, calculadas pelo método de isotitânio, com base na análise da própria rocha

Tomando-se como referência os dados obtidos com o método do isotitânio, com base na análise da própria rocha, encontrou-se o seguinte resultado, em ordem decrescente de remoção (Tabs. VI, VII):

a) rocha alterada

$$
\mathrm{CaO}>\mathrm{Na}_{2} \mathrm{O}>\mathrm{MgO}>\mathrm{K}_{2} \mathrm{O}>\mathrm{SiO}_{2}>\mathrm{MnO}>\mathrm{P}_{2} \mathrm{O}_{5}>\mathrm{Al}_{2} \mathrm{O}_{3}
$$

b) rocha semi-alterada,

$$
\mathrm{Na}_{2} \mathrm{O}>\mathrm{K}_{2} \mathrm{O}>\mathrm{CaO}>\mathrm{SiO}_{2}>\mathrm{MnO}>\mathrm{MgO}>\mathrm{P}_{2} \mathrm{O}_{5}>\mathrm{Al}_{2} \mathrm{O}_{3} .
$$


Foi observado por Levi e Melfi (1972) que as rochas básicas ígneas sofrem perda gradativa de cálcio, sódio, magnésio, potássio e silício, pela ordem decrescente de facilidade, o que está de acordo com os dados obtidos para a rocha alterada.

Tabela VI - Média da porcentagem de remoção (-) ou concentração (+) dos constituintes de rochas basálticas alteradas do Estado de São Paulo

\begin{tabular}{|c|c|c|c|c|}
\hline \multirow{2}{*}{ Constituinte } & \multicolumn{2}{|c|}{ Em relação à própria rocha inalterada } & \multicolumn{2}{|c|}{$\begin{array}{c}\text { Em relação à média de } 48 \text { amostras } \\
\text { de rocha inalterada }\end{array}$} \\
\hline & Isotitânio & Isoalumínio & Isotitânio & Isoalumínio \\
\hline $\mathrm{CaO}$ & $-95,4(-68,2)^{*}$ & $-94,2(-67,3)$ & $-95,2(-68,0)$ & $-94,4(-67,7)$ \\
\hline $\mathrm{Na}_{2} \mathrm{O}$ & $-93,2(-69,1)$ & $-91,6(-67,9)$ & $-93,5(-69,4)$ & $-92,6(-68,7)$ \\
\hline $\mathrm{MgO}$ & $-84,3(-50,8)$ & $-81,1(-48,9)$ & $-83,3(-50,2)$ & $-81,7(-49,3)$ \\
\hline $\mathrm{K}_{2} \mathrm{O}$ & $-78,1(-64,8)$ & $-74,0(-61,4)$ & $-82,2(-68,9)$ & $-79,7(-66,1)$ \\
\hline $\mathrm{SiO}_{2}$ & $-75,0$ & $-69,1$ & $-72,6$ & $-68,4$ \\
\hline $\mathrm{MnO}$ & $-70,6$ & $-65,0$ & $-72,3$ & $-67,8$ \\
\hline $\mathrm{P}_{2} \mathrm{O}_{5}$ & $-21,2$ & 0,28 & $-31,7$ & $-18,8$ \\
\hline $\mathrm{Al}_{2} \mathrm{O}_{3}$ & $-16,5$ & 0,0 & $-7,8$ & 0,0 \\
\hline $\mathrm{Fe}_{2} \mathrm{O}_{3}$ & 3,5 & 30,7 & 9,6 & 25,8 \\
\hline $\mathrm{TiO}_{2}$ & 0,0 & 33,9 & 0,0 & 18,3 \\
\hline $\mathrm{CO}_{2}$ & 248,4 & 343,2 & $-21,2$ & $-15,0$ \\
\hline $\mathrm{H}_{2} \mathrm{O}^{+}$ & 332,5 & 456,3 & 273,0 & 317,3 \\
\hline $\mathrm{H}_{2} \mathrm{O}^{-}$ & 685,6 & 837,2 & 642,2 & 711,6 \\
\hline
\end{tabular}

*O número entre parênteses representa valor de remoção sob a forma catiônica

Tabela VII - Média da porcentagem de remoção $(-)$ ou concentração $(+)$ dos constituintes de rochas basálticas semi-alteradas do Estado de São Paulo

\begin{tabular}{lccr}
\hline & \multicolumn{2}{c}{ Em relação à própria rocha inalterada } & \multicolumn{2}{c}{$\begin{array}{c}\text { Em relação à média de } 48 \text { amostras } \\
\text { de rocha }\end{array}$} \\
\cline { 2 - 5 } inalterada
\end{tabular}

*O número entre parênteses representa valor de remoção sob a forma catiônica

Levando-se em conta apenas o comportamento dos elementos e alcalino-terrosos, com os valores de perdas calculados sob a forma cationica, encontrou-se o seguinte resultado (Tab. VI, VII):

a) rocha alterada,

$$
\mathrm{Na}^{+}>\mathrm{Ca}^{2+}>\mathrm{K}^{+}>\mathrm{Mg}^{2+}
$$

b) rocha semi-alterada,

$$
\mathrm{Na}^{+}>\mathrm{K}^{+}>\mathrm{Ca}^{2+}>\mathrm{Mg}^{2+}
$$


de onde se conclui que o sódio foi o elemento mais removido enquanto que o magnésio foi o menos, havendo uma tendência de maior retenção do cálcio na camada semi-alterada, o que está de acordo com os dados de Levi e Melfi (1972). Dessa maneira, evidencia-se maior semelhança entre o comportamento desses dois materiais, o que não ficou evidente quando se considerou a perda desses elementos sob a forma de óxidos.

Hipólito e Valarelli (1972) realizaram estudos experimentais de alteração, com extrator Soxlet, de um diabásio de granulação fina, e verificaram que entre os elementos alcalinos e alcalino-terrosos, o íon $\mathrm{Na}^{+}$é o mais retido, ao contrário do resultado encontrado aqui, onde esse elemento é um dos mais facilmente removidos. Essa diferença de resultados pode ser uma evidência de que o método experimental empregado pode não estar reproduzido de maneira análoga ao fenômeno natural aqui estudado, a não ser que o método aqui empregado, para os cálculos de remoção, não estimem a contento o que se passou durante a alteração da rocha.

\section{BIBLIOGRAFIA}

ALMEIDA, F. F. M. de - 1946 - Basaltos do planalto de Maracaju. II Congresso Panamericano de Engenharia de Minas e Geologia, Petrópolis, Brasil (não publicado)

BATES, T.F. - 1962 - Halloysite and gibbsite formation in Hawaii. Clays and Clay Min. 9 th Conf. Pergamon Press, pp. 315-327

ESCOBAR, E. H., DEMATTÊ, J. L. I. e MONIZ, A. C. - 1971 - Gênese e classificação de alguns solos da bacia do ribeirão Tijuco Preto, município de Rio das Pedras, SP. I, Análise mineralógica da fração argila. Bragantia (no prelo)

HARRISON, J. B. - 1933 - The katamorphism of igneous rocks under humid tropical conditions. Harpenden, Imp. Bur. Soil Sci., 79 pp.

HYPÓLITO, R. e VALARELLI, J. V. - 1972 - Ordem de remoção de elementos lixiviados em experiência de alteração. XXVI Congres. Bras. Geologia, Belém, Pará

KOLTHOFF, I. M. e SANDELL, E. B. - 1943 - Textbook of quantitative inorganic analysis. New York, MacMillan Co., 794 pp.

KRAUSKOPT, K. B. - 1967 - Introdution to geochemistry. New York, McGraw-Hill Book Co., Inc., $721 \mathrm{pp}$.

LEINZ, V. - 1949 - Contribuição à geologia dos derrames basálticos do sul do Brasil. Bol. Fac. Filos. Ciên. Letr., USP, 103; Geologia, 5, 61 pp.

LEVI, F. e MELFI, A. J. - 1972 - Geochemical and mineralogical study of the first stages of weathering of basic and related rocks. Part 2, Geochemical study. Rev. Brasil. Geoc., 2 (1): 1-7

MELFI, A. J. - 1967 - Intemperismo de granito e diabásio no município de Campinas e arredores, Estado de São Paulo. Tese inédita. I. G. A., USP, 166 pp.

MELFI, A. J. e LEVI, F. - 1971 - Geochemical and mineralogical study of the first stages of weathering of basic and related rocks. Part 1 - Mineralogical study. Rev. Brasil. Geoc., 1 (1): $22-28$

MONIZ, A. G. e CARVALHO, A. - 1973 - Estudo mineralógico de solos derivados do arenito Bauru e rochas básicas da região noroeste do Estado de São Paulo. Bragantia (no prelo)

MONIZ, A. G. e JACKSON, M. L. - 1967 - Quantitative mineralogical analysis of Brasilian soils derived from basic rocks and slate. Wisconsin Soil Science Report 212, 73 pp.

PAIVA NETTO, J. E. de, ARGURI Jr., F., NASGIMENTO, A. C., ANGELERI, F. B. e SOUZA SANTOS, H. - 1956 - Características de alguns caulins dos arredores da cidade de São Paulo. Cerâmica, 2 (7): 111-144

PAIVA NETTO, J. E. de e NASGIMENTO, A. C. - 1957 - Diabásio e seus produtos de decomposição. XI Congres. Bras. Geologia, Salvador, Bahia

RÜEGG, N. R. - 1969 - Aspectos geoquímicos, mineralógicos e petrográficos de rochas basálticas da bacia do Paraná. Tese inédita. I. G. A., USP, 172 pp.

VALENTON, I. - 1972 - Bauxites - Developments in soil science 1. Amsterdam, Elsevier Publishing Co., 226 pp. 